\title{
Advances in Nondietary Management of Children with Atopic Dermatitis
}

\author{
James E. Rasmussen, M.D. \\ Professor of Dermatology and Pediatrics, Department of Dermatology, The University of Michigan, \\ Ann Arbor, Michigan 48109-0314
}

\begin{abstract}
This paper discusses recent advances in therapy of atopic dermatitis (AD), excluding those that include dietary management. Some of these therapies are anecdotal, experimental, or somewhat controversial. It is important to emphasize that physicians should not try what is new without first having given standard therapy a long and reasonable chance to succeed. This is important because AD does not last forever, and in many patients, mild disease heals spontaneously.
\end{abstract}

Rajka (1) believed that most cases of infantile atopic dermatitis (AD) heal at 2 to 3 years of age. Patients with widespread, severe involvement and those in whom the condition persists past the sixth year of age have a much worse prognosis. Roth and Kierland (2) conducted a 20-year follow-up on approximately 200 adult patients; $40 \%$ of those with mild AD had cleared, but only $29 \%$ of those with severe disease were similarly uninvolved.

\section{STANDARD THERAPY}

Standard therapy should be directed toward controlling the dryness, erythema, and pruritus that characterize $\mathrm{AD}$ in all patients at all ages. I believe that in order to ensure compliance, it should be simple and consist of only three or four basic items. My standard therapy uses mild to moderate corticosteroids ( $1 \%$ hydrocortisone or $0.025 \%-0.1 \%$ triamcinolone), daily bathing, avoidance of harsh soaps, and the liberal use of light to heavy lubricants depending on the season and the patient's tolerance. I insist that patients comply thoroughly with such a regimen before venturing into more difficult therapy. Giving patients complex instructions for modification of diet, pet control, means to increase the household humidity, avoidance of inhalants, avoidance of woolens, and major changes in bathing habits are usually too overwhelming and confusing to be attempted on the first visit. Information sheets are very useful for patients and parents.

Topical steroids should never be applied more than two to three times a day, whereas lubricants can be applied as needed for dryness. For patients whose disease is particularly severe, it is often more effective to begin with a one- to two-week course of the most potent topical corticosteroid available, followed by a gradual taper to low- to intermediatepotency agents. This often gives an immediate burst of relief, which can then be maintained with less strong drugs. Many physicians frequently use corticosteroids that are far too mild to obtain any therapeutic benefit.

Oral antihistamines, in my experience, are remarkably ineffective for the long-term management of $\mathrm{AD}$. Their initial usefulness is soon overcome by

Presented in part at the International Symposium on Atopic Dermatitis in Children: An Update, Rome, Italy, December 8$10,1988$.

Supported in part by the Babcock Fund. 
rapid development of tolerance, and I use them primarily as sedatives at bedtime.

It is important to establish realistic therapeutic goals and emphasize that AD cannot be cured. Far too many patients and parents believe that there is a "penicillin shot" that will provide long-lasting relief. 1 also emphasize that usually no laboratory tests are useful in routine management of the condition.

It is much better to insist on compliance with basic therapy before switching to more advanced therapy. If xerosis is not controlled, $A D$ will not usually improve.

\section{ADVANCED THERAPY}

Recent advances have been reported in the use of ultraviolet (UV) light; degerming infected skin; use of oil of evening primrose and eicosapentenoic acid (EPA), cyclosporine, chloroquin, and phosphodiesterase inhibitors; and avoiding the house dust mite.

\section{Systemic Steroids}

If the patient does not respond to outpatient therapy with mild topical steroids, lubricants, and antihistamines, and if the disease appears inflammatory (as opposed to lichenified), I consider a short course of oral corticosteroids (prednisone, $1 \mathrm{mg} / \mathrm{kg}$ ) for five to seven days. This drug is far too toxic to be used on a long-term basis except for those with life-threatening eczema and asthma.

Recently, Atherton's group (3) proposed a novel method of combining inhaled beclomethasone diproprionate plus the same agent given orally. In a placebo-controlled trial, 26 children with severe atopic eczema responded significantly better while receiving active agent than placebo. Skin involvement improved by about a half and there was a parallel reduction in itch. The authors obtained evidence of only very mild adrenal suppression. They believed the drug may be working at the local level of the gut to decrease gastrointestinal permeability to antigens.

\section{UV Light}

If topical and systemic corticosteroids together with lubricants and antihistamines do not produce a satisfactory response, the patient should be admitted to the hospital for a course of UV light similar to a modified Goekerman. Falk (4) evaluated 106 patients with atopic dermatitis who were given either ultraviolet $\mathrm{B}$ (UVB) or a combination of $\mathrm{A}$ and $\mathrm{B}$
(UVAB). Ninety-four percent of 54 patients who received UVAB were in remission after 18 treatments, compared to only $84 \%$ of 52 patients who received UVB after 23 treatments. This difference was statistically significant $(P<0.01)$. Neither treatment produced long-term responses. Thirty of 44 who were given UVB relapsed within three months after the last treatment, as did 27 of 51 who had UVAB.

Similar results were obtained in a smaller group of 56 patients studied by Midelfart, Stenvold, and Voloden (5). Thirty-three with severe AD were treated with UVB alone and 23 with UVAB. Fortyeight percent of the latter achieved complete remission compared to $27 \%$ of the former.

Atherton et al (6) treated 15 adolescents with severe eczema with psoralen, $0.6 \mathrm{mg} / \mathrm{kg}$ administered either two or three times a week. Patients also received $1 \mathrm{~J} / \mathrm{cm}^{2} \mathrm{UVA}$, with the dose gradually increasing by increments of 0.5 to $2.0 \mathrm{~J} / \mathrm{cm}^{2}$ at intervals of not less than one week, depending on skin tolerance and response. Fourteen of the 15 patients achieved near clearance, which took from 10 to 25 weeks (median 16 wks). Long-term remission was induced in nine.

Of the seven children with adequate data, six had growth velocity below the third percentile. During and after PUVA treatment, all six achieved growth velocity between the fiftieth and ninety-seventh percentiles.

\section{Controlling Infection}

Acute or flaring $\mathrm{AD}$ is frequently considered to have an infectious component. Numerous studies have shown that the skin of children with the condition is heavily colonized with coagulase-positive Staphylococcus aureus. Such was the case in both the involved and uninvolved skin of one group of patients studied by Leyden, Marples, and Kligman (7). Wet lesions of AD carry a tremendous burden of organisms, with lesser amounts being found in the dry, lichenified areas and smaller quantities present in clinically normal skin. The exact role of these organisms in the etiology of $\mathrm{AD}$ is not known for certain, but there may be an infectious and an allergenic component.

David and Cambridge (8) followed 190 children with $\mathrm{AD}$ prospectively for two and a half years. Seventy-six ( $40 \%$ ) had exacerbations of eczema due to bacterial infection and $25(15 \%)$ were admitted to hospital. Staphylococcus aureus was the most commonly recovered organism, being found in $97 \%$ of patients. 
Welbourn, Champion, and Parish, in a series of three classic papers (9-11), evaluated 122 patients with eczematous dermatitis. They showed a high percentage had immediate or four-hour (Arthuslike) responses to intradermal skin tests with staphylococcal antigen. In addition, the antigen was present on the skin surface and in the dermis, indicating percutaneous absorption. Approximately $60 \%$ of the patients had circulating antistaphylococcal immunoglobulin that was thought to participate in this hypersensitivity reaction.

Lever et al evaluated 49 patients with $A D$ in a double-blind, placebo-controlled, crossover trial of mupirocin, a topical antistaphylococcal antibiotic (12). All patients had heavy colonization of the skin with $S$. aureus prior to therapy. The bacterial count was significantly reduced by two weeks treatment with topical mupirocin twice a day, but not by the placebo. This reduction was accompanied by significant improvement in clinical severity, which was maintained over four weeks after therapy even though recolonization occurred during this period. Despite recolonization, clinical values remained improved and no serious side effects were observed.

Many of the new imidazole group of antifungal agents are also potent antibacterials. White and Blatchford (13) studied 19 patients with severe atopic eczema, who were treated with $2 \%$ miconazole plus $1 \%$ hydrocortisone cream for 14 days. Seventeen ( $89 \%$ ) demonstrated a significant improvement, and the combination was rated by $68 \%$ of the patients as better than previous therapy. Impetigo and ecthyma have also been successfully treated using the topical antifungals miconazole and sulconazole (14).

It is also generally accepted that the oral systemic antibiotics are useful for acute, weeping flares of $\mathrm{AD}$, particularly those that appear to be secondarily infected. There are no long-term studies on the degree of benefits from such therapy, and readers should always be aware of the potential for development of resistance after both topical and systemic therapy. Somewhat limiting the usefulness of the imidazoles and mupirocin is their relatively high cost for the small package.

\section{Dietary Supplementation with Oil of Evening Primrose and Eicosapentenoic Acid}

Wright and Burton (15) were among the first to conduct a double-blind, controlled, crossover study of various doses of oral evening primrose oil (EPO). They evaluated 99 patients with atopic eczema.
Sixty adults received two, four, or six capsules twice daily, while 39 children ( 8 mo-14 yrs of age) received one or two capsules twice a day. Each capsule contained $360 \mathrm{mg}$ of linoleic acid and $45 \mathrm{mg}$ of gamma-linolenic acid. The brand name Efamol was used throughout this study. In the low-dose groups in children and adults, no objective improvements were noticed, but patients did feel that pruritus was improved compared to placebo $(P<0.05)$. In the higher-dose groups, Efamol was better than placebo with regard to improvement in itch, scaling, and general severity. These responses occurred most prominently in the adults and less so among children. Adult patients in the high-dose group noted an overall improvement in severity of about $43 \%$. No side effects were reported. The authors felt that the mode of action was uncertain but that it might involve prostaglandin synthesis and the regulation of T lymphocytes.

A somewhat similar study was carried out by a Finnish group (16) who evaluated 25 patients with atopic eczema treated with either EPO $(n=14)$ or placebo $(n=11)$ for 12 weeks. Patients receiving EPO noted a statistically significant reduction in the severity and grade of inflammation as well as the percentage of body surface area involved. In addition, they felt less itchy and were perceived to be less dry. The oil caused a significant rise in the amount of dihomogamma-linolenic acid, but plasma levels of thromboxane and prostaglandins were not changed. Some authors have not been able to duplicate these beneficial clinical effects $(17,18)$, and in my uncontrolled clinical experience with over 50 cases, the results have been unimpressive.

Other authors studied the effect of dietary supplementation with EPA in the treatment of atopic dermatitis. In a 12-week, double-blind, randomized trial, 16 adults with $A D$ were given 10 max-EPA capsules daily ( $1.8 \mathrm{~g} \mathrm{EPA})$ and 15 controls were given 10 olive oil capsules a day (19). Severity scores assessed by the physician showed no statistically significant difference between the active and placebo groups. The patients' assessments, however, showed that max-EPA was better than placebo with regard to itch $(P<0.05)$, scale $(P<0.05)$, and total symptom score $(P<0.02)$. No significant difference was found between the groups with regard to topical steroid use during the trial.

\section{Phosphodiesterase Inhibitors}

Hanifin et al (20) have demonstrated that leukocytes from patients with AD show elevated activity 
of cyclic adenosine $3^{\prime}, 5^{\prime}$-monophosphate phosphodiesterase (PDE). The authors think that high PDE activity may allow increased IgE production as well as increased histamine release from basophils and mast cells. They believe that this is a basic defect of $\mathrm{AD}$.

To my knowledge there are no controlled trials of any known systemic PDE inhibitor since most of these drugs are too toxic for general use. Baer (21) advocates the use of papaverine, $150 \mathrm{mg}$ twice a day, on the grounds that it is significantly effective in decreasing pruritus in patients with $\mathrm{AD}$. The agent is believed to be a nontoxic, mild vasodilator, and has been in use since 1947. Baer (21) anecdotally reported his therapy of "hundreds of patients with moderately severe atopic dermatitis" and currently uses the $150-\mathrm{mg}$ timed-release capsules twice and occasionally three times a day. He believes that it reduces itching in the majority of cases of $\mathrm{AD}$, and in some patients "appears to have a truly striking effect." Baer noted that papaverine is an inhibitor of leukocyte PDE levels, citing the previous work of Hanifin et al.

Other PDE inhibitors such as caffeine, used as a $30 \%$ cream with $0.5 \%$ hydrocortisone, have been reported to be more effective than $0.5 \%$ hydrocortisone alone in patients with $A D(22)$. I have been able to locate nothing more in the literature on their use. I have found the use of papaverine to be without substantial effect in an uncontrolled series of 50 children with atopic eczema. In addition, $30 \%$ caffeine cream was without effect in localized areas of atopic eczema in my experience, and the potential for adverse reaction from percutaneous absorption appears significant.

\section{House Dust Mite Allergy}

Seventy-five percent of children with AD are sensitized to the house dust mite (HDM) by age 10 years. Beck and Hagdrup (23) analyzed 210 patients with $\mathrm{AD}$ and a positive prick test toward the animal (Dermatophagoides pteronyssimus), finding a high prevalence were born between May and November, compared with the expected distribution. Exposure to the mite is much more common during these months.

Vickers (24) noted that cell-mediated immunity to house dust mite antigen was demonstrated in 11 of 16 patients with atopic eczema compared to 2 of 14 controls. He reviewed studies showing the difficulty in hyposensitizing patients to the antigen, and emphasized his work with its avoidance using natamycin (Tymosil). This agent kills Aspergillus, which is the staple food of the house mite. Vickers believes house dust mite eczema is related to early morning flares, high IgE levels, and positive radioallergosorbent test (RAST). It may also be associated with a respiratory allergy. He treated 11 children in an open study in which natamycin was used throughout the house for a six-month period. Three children showed no change, three had moderate improvement, and the remaining five (45\%) had dramatic improvement in both skin and respiratory allergies.

Norris et al (25) showed that house dust mite could play a role in the pathogenesis of atopic eczema. Application of house dust mite solution or control to the antecubital or popliteal fossa showed a marked delayed local reaction in one-third of patients with $\mathrm{AD}$ due to house dust mite only. Further evidence supporting the role of the animal in the evolution of atopic dermatitis is the fact that HDMspecific IgE mirrors disease severity. Several uncontrolled studies show that avoiding the mite improves $\mathrm{AD}$.

\section{Desperation or Experimental Therapy}

For patients whose severe eczema is unresponsive to topical and intermittent use of oral corticosteroids, UV, and dietary supplementation, systemic cytotoxic agents may be useful. Morrison and Schulz (26) treated nine adult patients with intractable, severe $\mathrm{AD}$, using cyclophosphamide, $100 \mathrm{mg}$ daily, in eight cases, and azathioprine, 50 to $100 \mathrm{mg}$ daily, in the other. One patient treated with cyclophosphamide was subsequently given azathioprine. Patients were monitored carefully for development of leukopenia and thrombocytopenia. All reported remarkable improvement in an average of 13 weeks. The percentage of skin involvement, which before therapy had averaged $80 \%$, fell to an average of $7 \%$ during therapy. After the drugs were stopped, remissions varied from 1 to 60 months (average 24 mo). I have no experience with these drugs in adults or children.

Chloroquin, 125 to $250 \mathrm{mg} /$ day for three to six months, was used by Doring and Kreppel (27) to treat 62 patients suffering from $\mathrm{AD}$. In 46 the therapy resulted in such significant improvement that all systemic and other topical agents could be discontinued. Eight others reported substantial improvement but still used topical corticosteroids.

Hanifin's group (28) evaluated 18 patients with AD who were treated with injections of $50 \mathrm{mg}$ TP-5 (thymopoietin) or placebo three times weekly. Younger patients (age <34 yrs) responded to TP-5 
with much greater improvement in severity scores than those older than age 34 who received the hormone, or patients of either age group who were given placebo $(P<0.05)$. Immunologic abnormalities also reverted toward normal in patients given TP-5.

In a similar study, Harper et al (29) used thymostimulin (TP-1) in a double blind, controlled study of 29 adults with severe lifelong AD. Treatment consisted of twice-weekly injections of 1.5 $\mathrm{mg} / \mathrm{kg}$ for 10 weeks. A $20 \%$ reduction in clinical severity was noted when TP-1 was compared to placebo; however, T8 lymphopenia, high IgE levels, and high blood eosinophilia were unchanged in spite of the clinical improvement.

Finally, I would like to discuss the dermatologic applications of cyclosporine in $\mathrm{AD}$. Vanjoost et al (30) were the first to note the beneficial effects of the drug on severe disease. They treated two patients with severe drug-resistant disease with 5 $\mathrm{mg} / \mathrm{kg} /$ day of cyclosporine, and near complete remission $(>90 \%)$ was observed in both after four weeks of therapy. There was no correlation between trough blood levels and degree of improvement. After discontinuing cyclosporine, a gradual recurrence of lesions and pruritus was observed within three weeks.

Members of the Department of Dermatology at The University of Michigan treated five patients with low-dose cyclosporine and noted similarly good responses with a minimal amount of side effects (AK Gupta, JJ Voorhees, K Cooper, et al, personal communications, 1988). A double-blind, controlled study is now under way in our institution on low-dose cyclosporine in the treatment of $A D$. No pediatric patients, to my knowledge, have been treated systemically with this drug, however.

De Prost reported on his recent study of topical cyclosporine at the third international symposium on atopic dermatitis held in Oslo, Norway. This was a 20-patient, double-blind, controlled, paired comparison of a $10 \%$ topical cyclosporine gel with gel minus CSA. Patients were evaluated at 14 days for pruritus, erythema, lichenification, and scale xerosis. De Prost reported that all values improved in a statistically significant fashion, and that blood levels of cyclosporine were undetectable at topical dosing levels of $10 \mathrm{mg} / \mathrm{kg}$.

\section{REFERENCES}

1. Rajka G. Atopic dermatitis. In: Rook A, ed. Major problems in dermatology, vol 3. London: WB Saunders, 1975:7.
2. Roth HL, Kierland RR. The natural history of atopic dermatitis. Arch Dermatol 1964;89:209-217.

3. Heddle RJ, Soothill JF, Bulpitt CJ, Atherton DJ. Combined oral and nasal beclomethasone diproprionate in children with atopic eczema: a randomized, controlled trial. Br Med J 1984;289:651-654.

4. Falk ES. UV-light therapies in atopic dermatitis. Photo Dermatol 1985;2:241-246.

5. Midelfart K, Stenvold SE, Voloden G. Combined UVB and UVA phototherapy of atopic eczema. Dermatologica 1985;171:95-98.

6. Atherton DJ, Carabott F, Glover MT, Hawk JLM. The role of psoralen chemotherapy (PUVA) in the treatment of severe atopic eczema in adolescence. $\mathrm{Br}$ J Dermatol 1988;118:791-795.

7. Leyden JL, Marples RR, Kligman AM. Staphylococcus aureus in the lesions of atopic dermatitis. $\mathrm{Br} \mathrm{J}$ Dermatol 1974;90:525-531.

8. David TJ, Cambridge GC. Bacterial infection and atopic eczema. Arch Dis Child 1986;61:20-23.

9. Welbourn E, Champion RH, Parish WE. Hypersensitivity to bacteria in eczema. I. Br J Dermatol 1975;94:619-632.

10. Welbourn E, Champion RH, Parish WE. Hypersensitivity to bacteria in eczema. II. Br J Dermatol 1976;95:285-293.

11. Welbourn E, Champion RH, Parish WE. Hypersensitivity to bacteria in eczema. III. Br J Dermatol 1976:95:379-387.

12. Lever R, Hadley K, Downey D, Mackie R. Staphylococcal colonization in atopic dermatitis and the effect of topical mupirocin therapy. Br J Dermatol 1988;119:189-198.

13. White I, Blatchford N. The treatment of secondary bacterial infection in atopic eczema with miconazole plus hydrocortisone. Br J Clin Pract 1983;1:215-218.

14. Nolting S, Wolfgang B, Strauss BS. Treatment of impetigo and ecthyma. A comparison of sulconazole with miconazole. Int J Dermatol 1988;27:716-719.

15. Wright $\mathrm{S}$, Burton JL. Oral evening primrose seed oil improved atopic eczema. Lancet 1985;2:1120-1122.

16. Schalin-Karrila M, Mattila L, Jansen CT, Uotila P. Evening primrose oil in the treatment of atopic eczema: effects on clinical status, plasma phospholipid fatty acids and circulating blood prostaglandins. Br J Dermatol 1987;117:11-19.

17. Guenther L, Wexler D. Efamol and the treatment of atopic dermatitis. J Am Acad Dermatol 1987;14:860.

18. Bamford JT, Gibson RW, Renier CM. Atopic eczema unresponsive to evening primrose oil (linoleic and $\gamma$-linolenic acids). J Am Acad Dermatol 1985;13:959965.

19. Bjorneboe A, Soyland E, Bjorneboe GNE, Rajka G, Drevon CA. Effect of dietary supplementation with eicosapentenoic acid in the treatment of atopic dermatitis. Br J Dermatol 1987;117:463-469.

20. Hanifin JM, Butler JM, Chan SC. Phosphodiesterase levels in leukocytes from patients with atopic dermatitis. J Int Dermatol 1985;85:161-164.

21. Baer RL. Papaverine therapy in atopic dermatitis. J Am Acad Dermatol 1985;13:806-808. 
22. Kaplan HJ, Deman L, Rosenberg EW, Feigenbaum $\mathrm{S}$. Topical use of caffeine with hydrocortisone in the treatment of atopic dermatitis. Arch Dermatol 1978;114:60-62.

23. Beck HI, Hagdrup HK. Atopic dermatitis, house dust mite allergy and month of birth. Acta Dermatol Venereol 1987;67:448-451.

24. Vickers CFH. House dust mite and eczema. In: Orfanos CE, Stadler R, Golinick H, eds. Dermatology in five continents. Berlin: Springer-Verlag, 1988.

25. Norris PG, Schofield O, Camp RDR. A study of the role of house dust mite in atopic dermatitis. $\mathrm{Br} \mathrm{J}$ Dermatol 1988;118:435-440.

26. Morrison JGL, Schulz EJ. Treatment of eczema with cyciophosphamide and azathioprine. Br J Dermatol 1978;98:203-207.

27. Doring HF, Kreppel UM. Chloroquin-therapie der atopishen dermatitis. Z Hautkr 1987;62:1205-1213.

28. Hanifin JM, Cooper KD, Kang KIFI. Thymopoietin pentapeptide (TP-5) improves clinical parameters and lymphocyte subpopulations in atopic dermatitis. J Am Acad Dermatol 1983;8:372-377.

29. Harper JI, White IR, Staughton RCD, Hobbs JR. Thymostimulin (TP-1) therapy for atopic eczema. $\mathrm{Br}$ J Dermatol 1988;119:14.

30. Vanjoost T, Stolz E, Huele F. Efficacy of low dose cyclosporine in severe atopic disease. Arch Dermatol 1987;123:166-167. 
This document is a scanned copy of a printed document. No warranty is given about the accuracy of the copy. Users should refer to the original published version of the material. 